\title{
Snowstorm at the geomagnetic observatory
}

\author{
R. Čop \\ Institute Terra Viva, Sv. Peter 115, 6333 Sečovlje/Sicciole, Slovenia \\ Correspondence to: R. Čop (rudi@artal.si)
}

Received: 23 November 2014 - Published in Geosci. Instrum. Method. Data Syst. Discuss.: 15 January 2015 Revised: 4 July 2015 - Accepted: 28 July 2015 - Published: 12 August 2015

\begin{abstract}
The Sinji Vrh Geomagnetic Observatory (hereinafter the Observatory) is situated on Gora above Ajdovščina, a highland karst plateau, in the southwestern part of Slovenia. The Observatory operates in exceptional geological and meteorological conditions due to its location. The very first measurements at the time of initial tests showed that weather fronts induce changes in the local magnetic field. The first measurements intended to determine the value of this influence were carried out at the end of summer 2011. In 2013 the first such measurements were carried out in January. This article presents the results of these measurements, showing how the snowstorm induced changes in Earth's magnetic field.
\end{abstract}

\section{Sinji Vrh Geomagnetic Observatory}

Gora, above Ajdovščina, is a highland karst plateau. The Sinji Vrh Geomagnetic Observatory (hereinafter the Observatory) was built on its edge, which faces southwest (Paliska et al., 2010). The measuring post for the Observatory is located on the spot $\left(45.899094^{\circ} \mathrm{N}, 13.940047^{\circ} \mathrm{E}\right)$ above $\mathrm{Aj}$ dovščina, a town that lies at a height of $106 \mathrm{~m}$ above sea level, at the foothills of Gora. The measuring post lies northeast from Ajdovščina at a direct distance of $2.8 \mathrm{~km}$, where the Gora edge reaches a height of $867 \mathrm{~m}$ a.s.l. (above sea level).

In the summer of 2009 the first storm with lightning stroke in the location where the Observatory is situated was recorded and also confirmed by the neighbors. This storm was recorded during the test measurements that were meant to determine whether the location was suitable for a geomagnetic observatory. On 22 August 2009 at 20:08:50 UTC lightning stroke was registered in the middle of the second wave of a geomagnetic field with a period of $T=3.43 \mathrm{~h}$, as presented in Fig. 1.
The Observatory has a special construction and operates in exceptional geological and meteorological conditions because of its location, recommendations and the conditions prescribed by nature protection technicians (Čop and Deželjin, 2012). The first measurements intended to determine the value of this influence on the local geomagnetic field were carried out on 4 September 2011. They showed that the atmospheric discharge, the transitions of the weather fronts and the karst underground also induce changes in the local geomagnetic fields.

\section{Snowstorm on Gora}

The meteorological measurements for the Gora area are carried out at the meteorological station called AMP Otlica. This is an ecological meteorological station, which monitors the environmental changes on Gora. It is located $4.8 \mathrm{~km}$ away from the Observatory in the northwesterly direction.

The period of several months with the exceptionally abundant snowfalls, which marked the winter of 2012/2013, ended with the snowstorm on Gora on Tuesday, 15 January 2013. During the night from 14 to 15 January, the wind that had been blowing from the northeast changed its direction and started to blow from the south, as shown in Fig. 2. About 03:00 UTC, along with the change in the wind direction, the weather warmed and an hour later the snow started to fall. The first wave of the snowstorm diminished after $4 \mathrm{~h}$, when it became a little bit brighter as shown in Fig. 3. After intermediate calmness, at 10:20 UTC, the second wave of the storm reached Gora. At the same time air discharges started and of the registered lightning flashes only one occurred between a cloud and the ground. The next wave of the snowstorm passed over Gora at 13:30 UTC. At that time the wind speed decreased from the previous average value of 2.77 to 


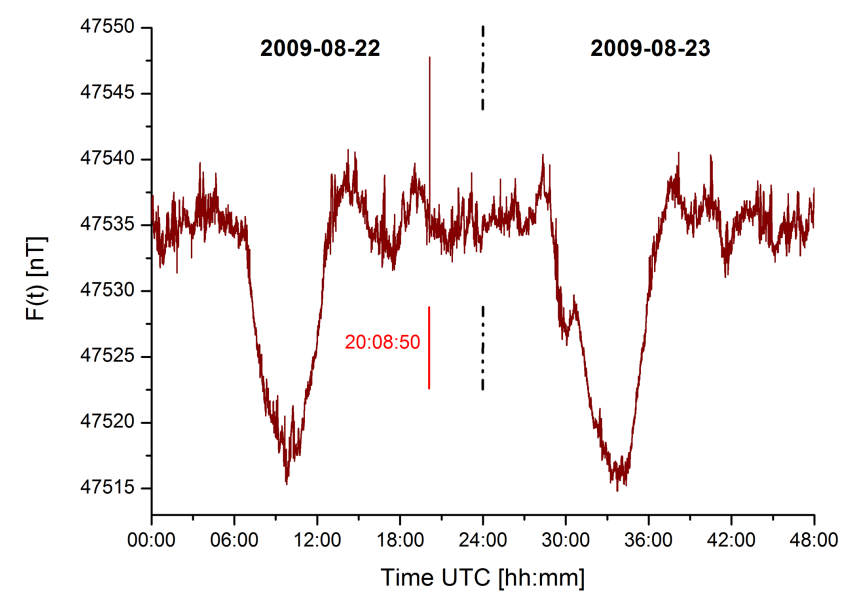

Figure 1. Daily variation of the geomagnetic field $F(t)$ at Sinji Vrh on two successive days in the summer of 2009.

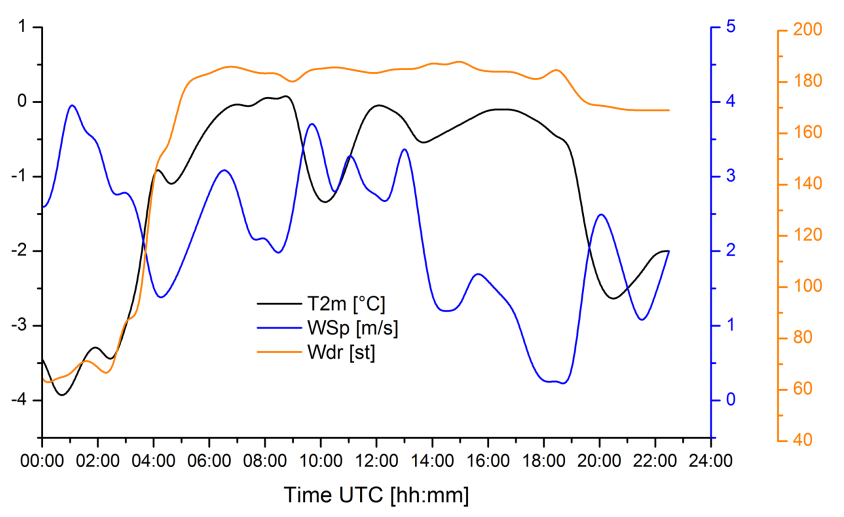

Figure 2. Temperature change $\left(T_{2 \mathrm{~m}}\right)$, wind speed $\left(W_{\mathrm{Sp}}\right)$ and wind direction $\left(W_{\mathrm{dr}}\right)$ measured at AMP Otlica during the 15 January 2013 snowstorm.

$1.29 \mathrm{~m} \mathrm{~s}^{-1}$, and this value was observed during the rest of the day, as well presented in Fig. 2.

The detailed analyses of a magnetogram in Fig. 4 show the occurrence of more atmospheric discharges during the halfhour period of the second wave of the snowstorm on Gora. Most of the electrical discharges happened within a cloud or between clouds. The only lightning flash, which occurred due to the electrical discharge of a negative charge between a cloud and the ground, happened at 10:20:45 UTC. It was among the last air discharges registered that day at the $\mathrm{Ob}$ servatory.

\section{Changes in the local geomagnetic field}

On Tuesday, 15 January 2013, when there was a snowstorm at the Observatory, our planet had its geomagnetic quiet day. This is evident from the diagram of the planetary $3 \mathrm{~h}$ range $K_{\mathrm{p}}$ indexes for that day (Estimated Planetary $K$ index, 2013), which showed that the $K_{\mathrm{p}}$ index reached its maximum value

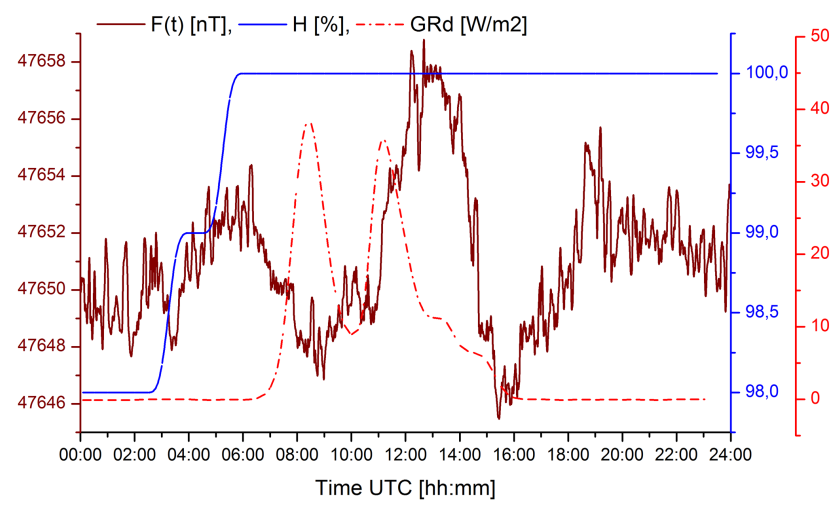

Figure 3. The local geomagnetic field's variations at the Observatory for the 15 January 2013 snowstorm and the values of humidity $(H)$ and solar radiation $\left(G_{\mathrm{Rd}}\right)$ measured the same day at AMP Otlica.

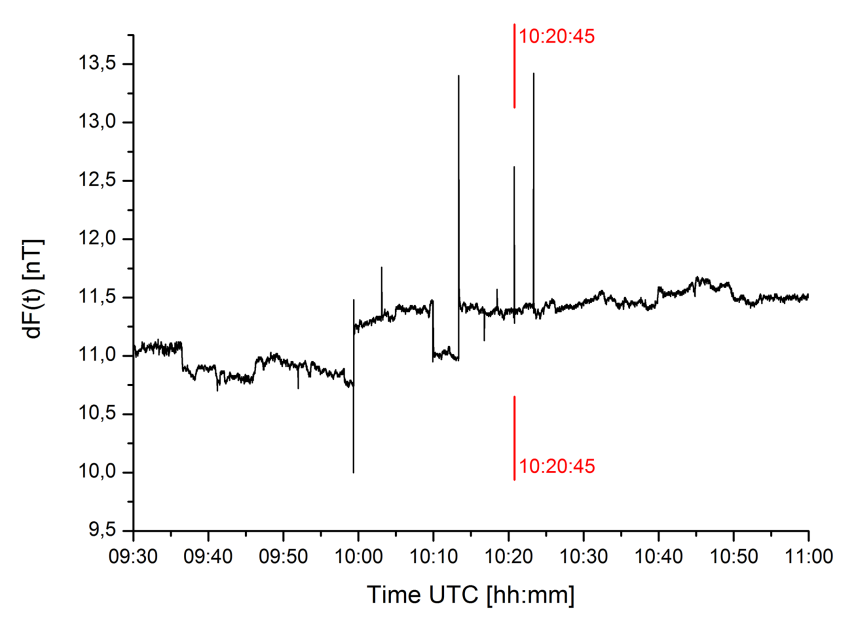

Figure 4. Change in the geomagnetic field $\mathrm{d} F(t)$ recorded during the measurements on 15 January 2013, at the beginning of the second part of the snowstorm on Gora.

of $K_{\mathrm{p}}=2$ during the $3 \mathrm{~h}$ range from 06:00 to 09:00 UTC. The planetary $\mathrm{Kp}$ indexes for the rest of that day were 1 or even lower. The planetary $3 \mathrm{~h}$ range $K_{\mathrm{p}}$ indexes for 5 January 2013 indicated that it was also a geomagnetic quiet day, as is evident from Fig. 5. The first half of that day, the planetary geomagnetic index was $K_{\mathrm{p}}=1$, and the second half of the day, it was $K_{\mathrm{p}}=0$.

For 15 January 2013 the magnetograms of changes in the absolute value of the geomagnetic field recorded at the Observatory are shown in Figs. 3 and 6. The characteristic change in the geomagnetic field began after 03:00 UTC and its duration was approximately $8 \mathrm{~h}$. This change was followed by a change with the same period but with approximately twice as high the amplitude.

Relating to the values of the planetary $K_{\mathrm{p}}$ index, this change in the geomagnetic field was local in character. The comparison of these measurements with the parallel mea- 


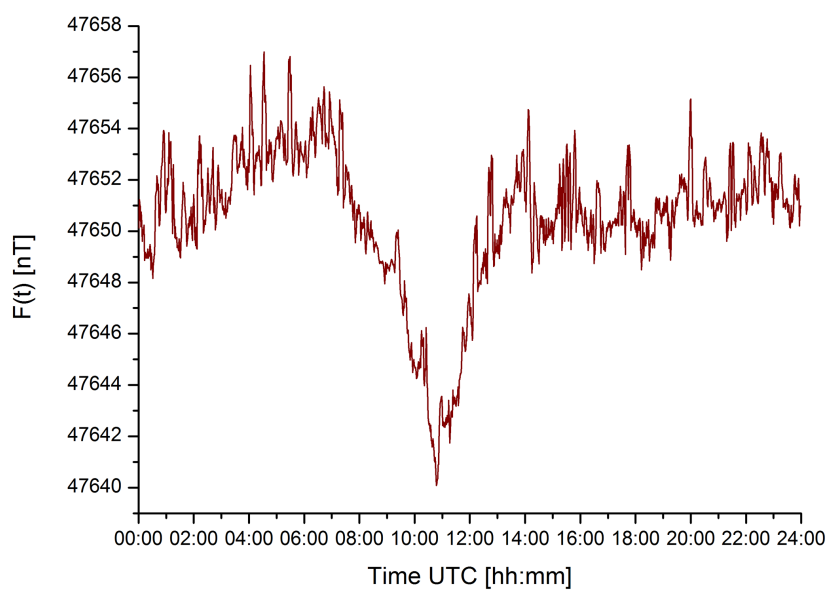

Figure 5. Daily variation of the geomagnetic field $F(t)$ at Sinji Vrh during the geomagnetic calm day on 5 January 2013.

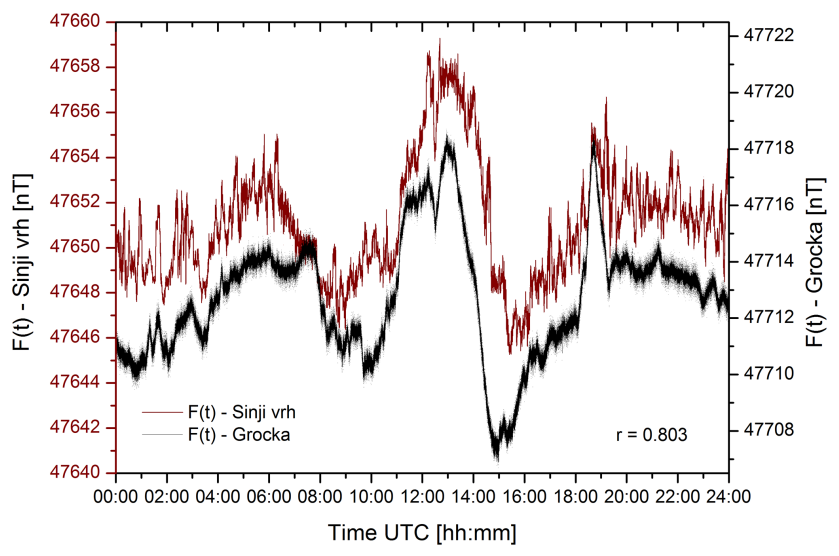

Figure 6. Change in the absolute value of the geomagnetic field vector $\boldsymbol{F}(t)$ recorded at the Observatory and the GCK Geomagnetic Observatory during the 15 January 2013 snowstorm.

surements of change in the geomagnetic field performed at the Grocka Geomagnetic Observatory (GCK), Serbia, on 15 January 2013 indicated the close similarity of the magnetograms. This means that the local geomagnetic disturbance was presented in the broader geographic area that also encompassed a large part of the Balkans. At the Observatory this disturbance started with the increase in relative humidity to $100 \%$ at the outdoor air temperature of $-3{ }^{\circ} \mathrm{C}$ and it was changing according to the solar radiation level, as presented in Fig. 3.

The parallel measurements on 15 January 2013 at the Observatory and the GCK Geomagnetic Observatory viewed in Fig. 6 had the value of a correlation coefficient $r=0.803$, as presented in Table 1. This is a little bit under the mean value of this coefficient $r_{\text {mean }}=0.854$ for both geomagnetic observatories (Čop et al., 2011). It proves that the impact of the weather front on the geomagnetic field was pretty much the
Table 1. Comparison of statistical values and the correlation of measurement results, obtained on 15 January 2013 at Sinji Vrh with those obtained at Grocka.

\begin{tabular}{lcccl}
\hline Observatory & $\begin{array}{c}\text { Mean } \\
\text { value } \mu \\
(\mathrm{nT})\end{array}$ & $\begin{array}{c}\text { Deviation } \\
\sigma \\
(\mathrm{nT})\end{array}$ & $\begin{array}{c}\text { Variation } \\
\mathrm{CV} \\
(\%)\end{array}$ & $\begin{array}{l}\text { Correlation } \\
r\end{array}$ \\
\hline Sinji Vrh & 47651.12 & 2.62 & 0.0055 & 1.00000 \\
Grocka & 47712.76 & 2.19 & 0.0046 & 0.803 \\
\hline
\end{tabular}

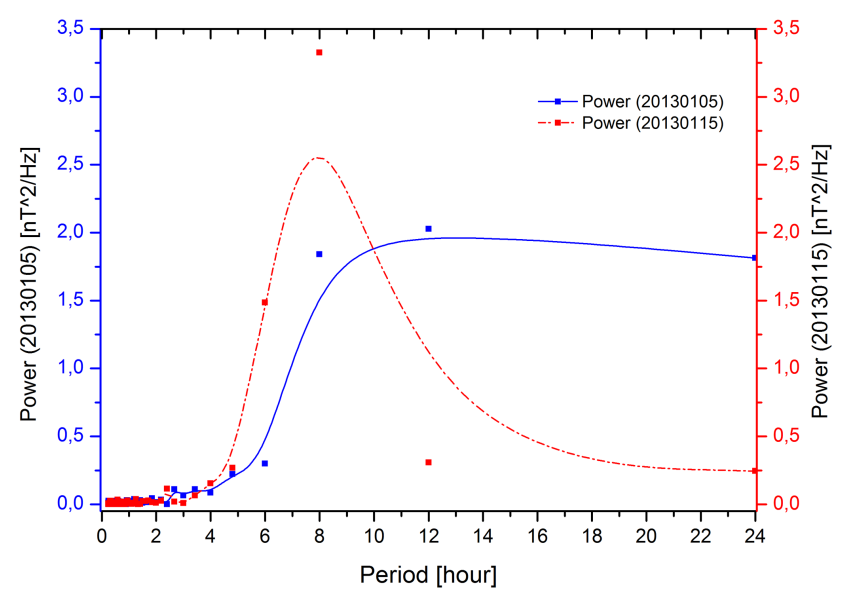

Figure 7. The power spectra of the local geomagnetic field at the Observatory during the snowstorm crossing on 15 January 2013 (20130115) and during the geomagnetic quiet day on 5 January 2013 (20130105).

same for both locations and that any distinction was in details only.

\section{Frequency characteristics}

The $1 \mathrm{~s}$ measuring data for each single day, discussed in the article, are the input data $f(t)$ for spectral analysis; their results are presented in Fig. 7. The comparison of values of the local geomagnetic field - measured and analyzed with regard to frequency during the snowstorm above Gora on 15 January 2013 - with those measured during the geomagnetic quiet day on 5 January 2013, shows that the signal power spectral density during the snowstorm increases sharply at the time period of $t=6 \mathrm{~h}$ and $t=7.5 \mathrm{~h}$.

The analyses in the frequency domain of the signals with the time period $t<2 \mathrm{~h}$, which were recorded during the snowstorm, did not show any significant increase in amplitudes of resonant frequencies. However, the time period of the signals was prolonged compared to its value during the geomagnetic quiet day and without snowstorm.

In the article presented, snowstorm has the characteristics of the mesoscale convective system (MCS). In Europe such weather systems arise mostly in the western part of the Mediterranean (Morel and Senesi, 2002). So, they also reach 
the southwestern part of Slovenia. Their influences on the geomagnetic field are relatively small. That is the reason why they should be clearly registered only during a geomagnetic quiet day, i.e., a solar quiet day $\left(S_{\mathrm{q}}\right)$, at the time of their passing over the geomagnetic observatory. The MCS systems are not cyclical events and their influences on the geomagnetic field are not part of the geomagnetic quiet day.

The geomagnetic quiet day is determined by daily variations of the geomagnetic field, recorded by magnetometers, on days without disturbances. From these measurements are eliminated lunar influences and post-perturbation effects (Campbell, 1986). The Sq magnetograms daily change their shape throughout the year and throughout the solar cycle. For a shorter time interval the Sq day is defined as a medium between the five quietest days in a month (Mayaud, 1980). The influences of the Moon on the geomagnetic field are relatively small and consequently definite only in a longer time period by harmonic analysis (Lindzen and Chapman, 1969).

In order to determine a solar quiet day from the numerical data, various algorithms were developed, and among them there is also frequency filtering of the magnetograms (Menvielle et al., 1995). The MCS systems appear in an acyclic manner and in shorter time periods; the special algorithms for subtracting their influences from the data are not obligatory (Hattingh et al., 1989; Fontes et al., 1995).

For the analysis of the frequency content of the signal $f(t)$, the ordinary Fourier transformation $F(\omega)$ is computed, expressed by Eq. (1).

$F(\omega)=\int_{0}^{\tau} f(t) \exp (i \omega t) \mathrm{d} t=A(\omega)+i B(\omega)$

The power spectral density $S(\omega)$ describes how the power of a signal or time series is distributed over different frequencies. It is definite in the interval from 0 to $T$ as the square value of the signal (Heinzel et al., 2002), as is presented in Eq. (2), where $F \wedge(\omega)$ is a truncated Fourier transform.

$S(\omega)=E\left[\left|F \wedge(\omega)_{T}^{2}\right|\right]$

The energy spectral density $E(\omega)$ is defined by Eq. (3), where $f\left(t^{\prime}\right)$ is the signal and $f^{*}(t)$ its complex conjugate value over a finite interval from 0 to $T$.

$$
\begin{aligned}
E\left[\left|F \wedge(\omega)_{T}^{2}\right|\right]= & \frac{1}{T} \iint_{0}^{T} E\left[f^{*}(t) f\left(t^{\prime}\right)\right] \\
& \exp \left(i \omega\left(t-t^{\prime}\right)\right) \mathrm{d} t \mathrm{~d} t^{\prime}
\end{aligned}
$$

For the calculation of the power spectral density for 5 and 15 January 2013 the fast Fourier transformation (FFT) was used and the results are presented in Fig. 7 where power spectra are expressed in respect to periods. If the frequency $\omega$ was not optimal, then the better numerical determination of functions $A(\omega)$ and $B(\omega)$ would be used (Střeštík, 1998).
The Fourier analyses are not always a good tool to analyze the signal, particularly if the curve is not smooth enough. In this case the wavelet analyses are more effective because they provide a signal approach for dealing with the local aspect of a signal and also remove noise from it (Walker, 1997; Kumar and Foufoula-Georgiou, 1997). As far as the influence of MCS weather fronts on the geomagnetic field is concerned, the wavelet analyses are very convenient for calculation of geomagnetic pulsation with frequencies from $7 \mathrm{mHz}$ to $0.5 \mathrm{~Hz}$ from $1 \mathrm{~s}$ data (Randarajan, 1989). These pulsations are in great correlation with the space weather (McPherron, 2000) and evidently also with the MCS weather fronts.

\section{Conclusions}

The systematic observation of weather fronts crossing the local area during many years and different seasons may provide enough data to understand their influence on the local geomagnetic field. The comparison of parallel measurements at the geomagnetic observatories in the vicinity would give more precisely the geographic size of influence of an individual weather front.

Some weather fronts passing the southwestern part of Slovenia have the characteristics of MCS systems. For this reason in this location it is also possible to study the transient luminous events in the ionosphere. They are initiated by the strong positive lightning strokes from cloud to ground and were well documented only in the past 2 decades (Pasko et al., 1996; Raizer et al., 1998; Chen et al., 2008). They produce magnetic pulses of extremely low frequency, lower than $1 \mathrm{kHz}$ (Cummer et al., 1998). Evidently these magnetic pulses have an impact on the instruments for measuring the variation of the geomagnetic field at the Observatory (Čop et al., 2014). Most probably they have influences also on our technology as well as on the biosphere (Deželjin and Čop, 2013).

Acknowledgements. I wish to express my gratitude to all institutions that provided the data used in this article:

- Slovenian Environment Agency (ARSO - Agencija Republike Slovenije za okolje), Meteorology Office, for the results of measurements of meteorological station AMP Otlica for 15 January 2013;

- Milan Vidmar Electric Power Research Institute, EiMV, Ljubljana, for the Report on Lightning Stroke no. 30/1/1/2013; and

- Grocka Geomagnetic Observatory, Serbia, for the results of measurements of change in the geomagnetic field for 15 January 2013.

The author is also grateful to all who contributed to this article, especially to the associated editor Lev Eppelbaum, anonymous referees and editorial supporters.

Edited by: L. Eppelbaum 


\section{References}

Campbell, H. W.: The regular Geomagnetic-Field Variation During Quiet Solar Conditions, in: Vol. 3, Geomagnetism, edited by: Jacobs, J. A., Academic, London, 385-460, 1986.

Chen, B. A., Kuo, C.-L., Lee, Y.-J., Su, H.-T. S., Hsu, R.-R., Chern, J.-L., Frey, U. H., Mende, B. S., Takahashi, Y., Fukunishi, H., Chang, Y.-S., Liu, T.-Y., and Lee, L.-C.: Global distributions and occurrence rates of transient luminous events, J. Geophys. Res., 113, A08306, doi:10.1029/2008JA013101, 2008.

Čop, R., Deželjin, D., Mihajlović, J. S., and Kosovac, P.: Preliminary Measurements of Geomagnetic-field Variations in Slovenia, Elektrotehniški vestnik, 78, 96-101, 2011.

Čop, R. and Deželjin, D.: Transmission of Measuring Data from the Sinji Vrh Geomagnetic Observatory, Proceedings of the XVth IAGA Workshop on Geomagnetic Observatory Instruments, Data Acquisition, and Processing, 4-14 June 2012, San Fernando, Cadiz, Spain, Real Instituto y Observatorio de la Armada, San Fernando, Spain, 2012.

Čop, R., Milev, G., Deěljin, D., and Kosmač, J.: Protection against lightning at a geomagnetic observatory, Geosci. Instrum. Method. Data Syst., 3, 135-141, doi:10.5194/gi-3-135-2014, 2014

Cummer, A. S., Inan, S. U., Bell, F. T., and Barrington-Leigh, P. C.: ELF radiation produced by electrical currents in sprites, Geophys. Res. Lett., 25, 1281-1284, 1998.

Deželjin, D. and Čop, R.: IT System for Alarming of Possible Health Risks Caused by Geomagnetic Storms, Global Telemedicine and e-Health Updates: Knowledge Resources, 6, 512-515, 2013.

Estimated Planetary $K$ index (3-hour data): Begin: 14 January 2013, 00:00 UTC, NOAA; Space Weather Prediction Center, Boulder, CO, USA, http://www.swpc.noaa.gov/ftpdir/warehouse/2013/ 2013_plots/kp/20130116kp.gif, last access: 2 December 2013.

Fontes, S. L., Seixas, N. A. B., Figuemedo, I., and Motta, C. M.: Automatic K-Index Determination Using a Variable Cut-Off Frequency Filtering Procedure, J. Geomag. Geoelect., 47, 607-619, 1995.

Hattingh, M. Loubser, L., and Nagtegaal, D.: Computer K-index estimation by a new linear-phase, robust, nonlinear smoothing method, Geophys. J. Int., 99, 533-547, 1989.
Heinzel, G., Rudiger, A., and Schilling, R.: Spectrum and spectral density estimation by the Discrete Fourier transform (DFT), including a comprehensive list of window functions and some new at-top windows, Max-Planck-Institut für Gravitationsphysik (Albert-Einstein-Institut), Hannover, 2002.

Kumar, P. and Foufoula-Georgiou, E.: Wavelet analysis for geophysical applications, Rev. Geophys., 35, 385-412, 1997.

Lindzen, S. R. and Chapman, S.: Atmospheric Tides, Space Sci. Rev., 10, 3-188, 1969.

Mayaud, P. N.: Derivation, Meaning, and Use of Geomagnetic Indices. Geophysical Monograph, American Geophysical Union, Washington, 1980.

McPherron, L. R.: Magnetic Pulsations: Their Sources and Relation to Solar Wind and Geomagnetic Activity, University of California, Los Angeles, Institute of Geophysics and Planetary Physics, Los Angeles, 2000.

Menvielle, M., Papitashvili, N., Hakkinen, L., and Sucksdorff, C.: Computer production of $K$ indices: review and comparison of methods, Geophys. J. Int., 123, 866-886, 1995.

Morel, C. and Senesi, S.: A climatology of mesoscale convective systems over Europe using satellite infrared imagery, II: Characteristics of European mesoscale convective systems, Q. J. Roy. Meteorol. Soc., 28, 1973-1995, 2002.

Paliska, D., Čop, R., and Fabjan, D.: The Use of GIS-based Spatial Multi-criteria Evaluation in the Selection Process for the New Slovenian Geomagnetic Observatory Site, Ann. Ser. Hist. Natur., 20, 1-8, 2010.

Pasko, P. V., Inan, S. U., and Bell, F. T.: Sprites as luminous columns of ionization produced by quasi-electrostatic thundercloud fields, Geophys. Res. Lett., 23, 649-652, 1996.

Raizery, P. Y., Milikh, M. G., Shneidery, N. M., and Novakovskiz, V. S.: Long streamers in the upper atmosphere above thundercloud, J. Physics D, 31, 3255-3264, 1998.

Randarajan, G. K.: Indices of Geomagnetic Activity, in: Vol. 3, Geomagnetism, edited by: Jacobs, J. A., Academic Press, London, 323-384, 1989.

Střeštík, J.: Spectrum of geomagnetic activity in the period range 560 days: possible lunar influences, Ann. Geophys., 16, 804-811, doi:10.1007/s00585-998-0804-4, 1998.

Walker, S. J.: Fourier Analysis and Wavelet Analysis, Notices AMS, 44, 658-670, 1997. 